\title{
Estudo da vida útil de queijo Minas
}

\author{
Study of Minas cheese shelf life
}

\author{
Naiane, SANGALETTI ${ }^{1}$, Ernani PORTO ${ }^{1 *}$, Solange Guidolin Canniatti BRAZACA ${ }^{1}$, \\ Cintia Akemi YAGASAKI ${ }^{1}$, Rebeca Camacho DALLA DEA ${ }^{1}$, Mariana Vieira da SILVA ${ }^{1}$
}

\section{Resumo}

Foi avaliado o prazo de vida útil do queijo Minas frescal armazenado a $4{ }^{\circ} \mathrm{C}$ por 30 dias, através de análises microbiológicas e físicoquímicas. Três lotes (A, B e C) de uma mesma marca foram analisados nos dias 1, 10, 20 e 30 após a fabricação. Foram feitas as contagens de microrganismos psicrotróficos, lipolíticos, proteolíticos, bactérias lácticas e mesófilas, que apresentaram um crescimento contínuo durante o período, atingindo contagens médias, respectivamente:, piscotróficos $=11,63$; lipolíticos $=10,34$; proteolíticos $=9,75$ bactérias lácticas $=9,53$; e mesófilos = 11,47 log UFC.g-1 ${ }^{-1}$ A população de Escherichia coli desenvolveu-se em um dos lotes e Staphylococcus coagulase +e Salmonella não foram detectados. No mesmo período, observou-se a redução de 0,81 no valor do pH e o aumento do ácido láctico (0,026\%). Não se observou redução na gordura (21,5\%), embora a quantidade de ácidos graxos livres tenha aumentado em $0,22 \mathrm{mg} \mathrm{KOH.g}{ }^{-1}$ de gordura. A proteína variou de 21,30 a 22,10\% sem diferença significativa. O índice de extensão da proteólise aumentou $3 \%$ a cada 10 dias. Apenas em um dos lotes (C) no $30^{\circ}$ dia o produto apresentou-se impróprio para o consumo com $1,7 \times 10^{4} \mathrm{NMP}^{-1}{ }^{-1}$ de E. coli.

Palavras-chave: avaliação físico-química; avaliação de vida útil; laticínios; microbiologia; queijo Minas frescal.

\begin{abstract}
The shelf life of the Minas fresh cheese was evaluated during 30 days of storage at $4{ }^{\circ} \mathrm{C}$ through microbiological and physical-chemical analyses. Three lots (A, B, and C) of the same brand and from the same dairy were analyzed on days 1, 10, 20, and 30 after production. The counting of the colonies of psicrotrophic microorganisms, lypolitics, proteolytics, lactic acid bacteria and mesophilic bacteria showed a continuous growth reaching 8.50, 8.04, 8.30, 6.05 and $7.7 \mathrm{log}$ UFC.g ${ }^{-1}$, respectively. The Escherichia coli colony grew in one of the lots studied, and Staphylococcus coagulase + and Salmonella were not detected. In the same period, there was reduction of $\mathrm{pH}(0.81)$ and the increase of the lactic acid (0.026\%). No cheese fat decrease was observed (21.5\%) although the amount of free fat acid increased in $0.22 \mathrm{mg} \mathrm{KOH} / \mathrm{g}$ of fat. The protein varied from $21.30 \%$ to $22.10 \%$, which is not a significant difference. The proteolysis extension index increased $3 \%$ every 10 days. On the $30^{\text {th }}$ day, the sample of the lot C proved improper for the consumption with $1.7 \times 10^{4} \mathrm{NMP}^{-1} \mathrm{~g}^{1} \mathrm{de}$ E. coli.

Keywords: shelf life; Minas soft cheese; dairies; microbiology; physical-chemical analyzes.
\end{abstract}

\section{Introdução}

O queijo Minas frescal é um dos queijos mais populares do País, sendo consumido por todas as camadas da população. $\mathrm{O}$ queijo Minas frescal é um produto de massa crua, com alto teor de umidade (46 a 55\%), não maturado e que deve ser consumido nos primeiros quinze dias após sua fabricação, pois é altamente perecível mesmo sob refrigeração (SILVA et al., 2003, PERRY, 2004, HOFFMAN; SILVA; VINTURIM, 2002, FURTADO, 2005). Os queijos de massa mole com $\mathrm{pH}$ alto e umidade elevada permitem o desenvolvimento de muitos microrganismos (VARNAN; SUTHERLAND, 1994). O queijo Minas frescal não é padronizado e sua composição é variável: apresenta de 12 a 18\% de proteína (ROSA, 2004, MACHADO et al. 2004, MARQUES; OLIVEIRA, 2004); gordura de 20,5\% (ROSA, 2004) até $29,22 \%$ (MACHADO et al., 2004). Durante a fabricação do queijo Minas podem ocorrer perigos que irão comprometer o produto final, dentre eles destacam-se: alta contaminação microbiológica da matéria-prima, recontaminação do leite pós-pasteurizado, temperaturas inadequadas de fabricação e de armazenamento (SANTOS; NOGUEIRA; CUNHA, 1995). Assim, as boas práticas de fabricação e as medidas de sanificação durante o processamento são cruciais para a garantia de um produto de qualidade (PICOLI et al., 2006).

Após a pasteurização o leite não possui uma microbiota dominante, assim na elaboração de certos queijos procede-se à adição de culturas láticas, as quais fermentam a lactose, formando ácido láctico, o que diminui o $\mathrm{pH}$ e beneficia a ação da renina (ESKIN, 1990). Na fabricação do Minas frescal, isso é opcional, permitindo a aplicação direta do ácido láctico (BRASIL, 1997). As bactérias lácticas causam transformações bioquímicas de lipídios e proteínas, que aumentam o índice de proteólise e lipólise no queijo Minas frescal produzido com leite pasteurizado (ISEPON; OLIVEIRA, 1993, ESKIN, 1990).

Recebido para publicação em 10/7/2007

Aceito para publicação em 14/4/2008 (002663)

${ }^{1}$ Escola Superior de Agricultura Luiz de Queiroz - ESALQ, Universidade de São Paulo - USP, Av. Pádua Dias, 11, CP 9, CEP 13418-900, Piracicaba - SP, Brasil,

E-mail: eporto@esalq.usp.br

${ }^{*}$ A quem a correspondência deve ser enviada 
A contagem padrão em placa (PCA) pode fornecer uma ideia do grau da contaminação do alimento e auxiliar na previsão do seu tempo útil de conservação (SILVA; JUNQUEIRA; SILVEIRA, 2001, JAY, 1994). Entre os microrganismos encontrados estão os principais contaminantes do leite: Bacillus, Enterobacteriaceae, Clostridium, Corynebacterium e Streptococcus.

O grupo coliforme fecal é restrito aos coliformes que vivem exclusivamente no trato gastrointestinal de humanos e de animais de sangue quente. Isto inclui pelo menos três gêneros: Escherichia coli, Klebsiella e Enterobacter (HITCHINS; HARTMAN; TODD, 1992, SILVA; JUNQUEIRA; SILVEIRA, 2001). Dentre esses microrganismos, a bactéria Escherichia coli é a mais conhecida e a mais facilmente diferenciada dos microrganismos não fecais e é o melhor indicador de contaminação fecal conhecido até o momento (SILVA; JUNQUEIRA; SILVEIRA, 2001).

Os estafilococos encontram-se amplamente disseminados no ambiente, o seu reservatório principal é o homem e os outros animais (CHAVES, 1993). Produzem intoxicação alimentar pela produção de uma enterotoxina termoestável (SIQUEIRA, 1995). O Staphylococcus aureus é frequentemente encontrado em leite e seus derivados. As infecções estafilocócicas na glândula mamária bovina representam um reservatório de culturas toxigênicas deste microrganismo (FLOWERS et al., 2005). O queijo também é veículo da Salmonella sp., e em 1984 no Canadá registrou-se um surto com 1500 casos confirmados, no qual as células dos microrganismos sobreviveram no queijo por 8 meses sob refrigeração (FLOWERS et al., 2005). Trabalhos realizados por Ávila e Galo (1996) e Carvalho, Viotto e Kuaye (2007) apontaram ausência de Salmonella sp. em queijo Minas frescal, o que não significa que não estejam presentes nesse tipo de produto, mas que não foram detectados na amostra analisada de $25 \mathrm{~g}$.

O grupo das bactérias psicrotróficas cresce em temperaturas de 2 a $7{ }^{\circ} \mathrm{C}$, independente de sua temperatura ótima de crescimento (ROBINSON, 1987). Estes microrganismos são termossensíveis e facilmente destruídos pela pasteurização, porém produzem enzimas extracelulares (lipases e proteases) que são termorresistentes, permanecendo no leite após a pasteurização (MOURA, 1997). É um grupo muito importante em produtos que são conservados sob refrigeração por períodos entre 1-4 semanas (PERRY, 2004). Muitas destas bactérias responsáveis pela deterioração de produtos lácteos refrigerados são altamente proteolíticas e podem causar defeitos no sabor (FRANK; CHRISTEN; BULLERMAN, 2005).

Os lipídios presentes em alimentos podem sofrer oxidação ou degradação hidrolítica. (MCSWEENEY; SOUSA, 2000). Em queijos, a lipólise causada pelas bactérias lipolíticas, hidrolisa os triacilgliceróis com liberação de ácidos graxos e glicerol (FURTADO; CHANDAN, 1983), uma das principais causas do ranço (PERRY, 2004). A proteólise no queijo pode ser devida às enzimas proteolíticas do coalho adicionado, assim como das enzimas do fermento lático adicionadas ao leite. Outros microrganismos porventura presentes, como resultado de contaminação ambiental, também podem contribuir para essa degradação, com destaque para os psicrotróficos (WOLFSCHOON-POMBO, 1983). O Minas frescal é um queijo consumido sem maturação, porém, a tecnologia de fabricação e consequentemente a proteólise, influenciam decisivamente na consistência, sabor e durabilidade do produto (WOLFSCHOON-POMBO; LIMA, 1989).

O objetivo deste trabalho foi avaliar as alterações de queijos Minas frescal durante o armazenamento por 30 dias a $4{ }^{\circ} \mathrm{C}$, por meio de análises microbiológicas e físico-químicas.

\section{Material e métodos}

O projeto foi desenvolvido no Laboratório de Laticínios do Departamento de Alimentos, Agroindústria e Nutrição da Escola Superior de Agricultura “Luiz de Queiroz” (ESALQ-USP), em Piracicaba, SP.

\subsection{Seleção e tratamento do queijo}

Para a seleção do queijo, seis marcas comercializadas em supermercados de Piracicaba, SP, com registro no SIF (Serviço de Inspeção Federal) foram analisadas, sendo apenas uma selecionada por ser a única que atendeu aos requisitos microbiológicos determinados pela legislação vigente (BRASIL, 2001).

A partir da marca selecionada, os queijos foram adquiridos diretamente do laticínio totalizando três lotes do produto (denominados A, B e C) e analisados um dia após sua fabricação. As peças de queijo foram armazenadas em incubadora BOD a $4{ }^{\circ} \mathrm{C}$, durante o período de 30 dias. Foram analisadas 2 peças de queijo de $250 \mathrm{~g}$ por período. Cada peça foi analisada em duplicata nos diferentes períodos de armazenamento $(1,10$, 20 e 30 dias). Foram 3 repetições do experimento, cada uma referindo-se a um lote diferente.

As análises microbiológicas e físico-químicas foram realizadas no mesmo período.

\subsection{Microbiologia}

\section{Preparo das amostras}

As embalagens foram desinfetadas com álcool 70\%. Foram retiradas porções de várias regiões da peça, cortadas em pequenos pedaços e $25 \mathrm{~g}$ homogeneizados em homogeneizador Stomacher juntamente com $225 \mathrm{~mL}$ de água peptonada $0,1 \%$ estéril (diluição $10^{-1}$ ). A partir desta foram feitas sucessivas diluições decimais, tantas quanto necessárias, conforme descrito no Standard Methods for the Examination of Dairy Products - APHA (1992).

\section{Análises microbiológicas}

As análises microbiológicas dos queijos foram realizadas seguindo os procedimentos gerais (diluições, plaqueamento, repetições e contagens) descritos no APHA (1992).

Foi determinado Escherichia coli pela técnica dos tubos múltiplos em meio Caldo Lauril Sulfato Triptose suplementado com 50mg/L de 4-metil-umbeliferil- $\beta$-D-glucoronídeo (LST-MUG/MERCK) com tubos de Durhan invertidos e 
incubados a $35^{\circ} \mathrm{C}$ por 24 a 48 horas. O resultado foi expresso em Número Mais Provável por grama (NMP/g).

Para Staphylococcus coagulase positiva utilizou-se o método de plaqueamento em superfície, em meio Agar Baird Parker (MERCK) com incubação a $35^{\circ} \mathrm{C}$ por 48 horas. $\mathrm{Na}$ análise de Salmonella sp., utilizou-se o teste presença ou ausência em $25 \mathrm{~g}$. As bactérias lácticas foram determinadas em meio Man, Rogosa e Sharpe Agar (MRSA), com incubação por 3 dias a $35^{\circ} \mathrm{C}$.

As bactérias mesófilas foram determinadas em placas com Plate Count Agar (PCA) incubadas a $35^{\circ} \mathrm{C}$ por 48 horas. As bactérias psicrotróficas totais também foram determinadas em PCA, mas incubadas a $7^{\circ} \mathrm{C}$ por 10 dias. $\mathrm{O}$ ágar Caseinato de Cálcio (MERCK) foi utilizado para determinar as bactérias psicrotróficas proteolíticas por plaqueamento em superfície, com incubação por 10 dias a $7^{\circ} \mathrm{C}$. As bactérias psicrotróficas lipolíticas foram inoculadas em placas com ágar Tributirina (AT) por plaqueamento em profundidade e incubadas a $7^{\circ} \mathrm{C}$ por 10 dias. Os resultados foram expressos em Unidade Formadora de Colônias por grama de queijo (UFC.g-1).

\subsection{Físico-química e químicas}

\section{Preparo das amostras}

Após realizar as análises microbiológicas, o queijo restante foi triturado com gral e pistilo e homogeneizado antes de ser submetido às análises físico-químicas. Todas as análises foram feitas em duplicata.

\section{Análises físico-químicas e químicas}

Foram realizados os testes de $\mathrm{pH}$ pelo método potenciométrico e a acidez titulável (\% ácido láctico) (APHA, 1992). O teor de gordura (\% gordura) foi determinado pelo Método de Babcock (APHA, 1992). Para quantificar o grau de lipólise dos queijos foi determinado o teor de ácidos graxos livres (AGL), segundo o método tritimétrico descrito por Caboni, Zannoni e Lercker (1990), no qual o índice de acidez é expresso em mg de $\mathrm{KOH}$ para neutralizar um grama de gordura. A porcentagem de proteína foi determinada através do teor de nitrogênio total multiplicado pelo fator 6,38, através do método Kjeldahl, de acordo com o (APHA, 1992).

Os teores de nitrogênio total (NT) e de nitrogênio solúvel em pH 4,6 (NS) dos queijos Minas frescal foram determinados pelo método Kjeldahl, segundo Gripon et al. (1975). O índice de extensão da hidrólise é calculado pela relação entre a porcentagem de nitrogênio solúvel em $\mathrm{pH}$ 4,6 e a porcentagem de nitrogênio total (Equação 1).

Índice de extensão $=\frac{\text { Nitrogênio solúvel }}{\text { Nitrogênio total }} \times 100$

\subsection{Análise estatística}

O delineamento experimental para as amostras foi inteiramente casualizado, com 4 repetições para todas as análises por período (duas peças de queijo analisadas em duplicata). Os dados foram submetidos à análise de variância do programa SAS versão 8.0 (SAS, 1988), e as diferenças entre as médias foram testadas pelo teste de Tukey ao nível de 5\% de significância.

\section{Resultados e discussão}

\subsection{Seleção do queijo}

De seis marcas coletadas em supermercados de Piracicaba, SP, com registro no SIF, apenas uma delas se enquadrou como própria para consumo, a qual foi submetida ao estudo de vida útil. As outras cinco marcas $(83,33 \%)$ apresentaram contagens de Escherichia coli acima de $2,4 \times 10^{3} \mathrm{NMP}^{-1}$. Como essa bactéria pertence ao grupo dos coliformes fecais e esse valor está acima do permitido pela legislação vigente (BRASIL, 2001), esses lotes foram considerados impróprios para o consumo. Isso não é incomum, pois Lisita (2005) analisou queijos Minas no final da produção em um laticínio com SIF e detectou amostras já condenadas antes da comercialização, com contagem de $1,1 \times 10^{8} \mathrm{NMP.g}^{-1} \mathrm{de}$ coliformes fecais. Os resultados obtidos nessa etapa reforçam a necessidade de aplicação de boas práticas higiênicas na produção do queijo Minas para evitar esse tipo de problema.

\subsection{Análises microbiológicas}

$\mathrm{Na}$ Tabela 1 observa-se que os queijos da marca selecionada apresentaram-se próprios para o consumo durante o período de 30 dias, exceto em um dos lotes (lote C), o qual apresentou no $30^{\circ}$ dia de armazenamento contagem de $1,7 \times 10^{4} \mathrm{NMP}^{-1}$ de E. coli , enquadrando-se como impróprio para o consumo conforme Resolução Colegiada (RDC) no 12 da Agência Nacional de Vigilância Sanitária (2001). A contagem dos estafilococos coagulase positiva permaneceu com $<10,0$ UFC. $g^{-1}$ e a Salmonella sp. foi ausente em $25 \mathrm{~g}$ durante todo o período em todas as amostras.

Na pesquisa de Carvalho, Viotto e Kuaye (2007), que avaliou 97 amostras de queijo Minas frescal comercializados na cidade de Campinas, SP, $29 \%$ das amostras foram condenadas por elevada contagem de coliformes de origem fecal e $12,9 \%$ por contaminação excessiva de Staphylococcus coagulase positiva, conforme o padrão estabelecido pela legislação vigente (BRASIL, 2001), contudo Salmonella sp. não foi detectada nas amostras. Esses resultados foram piores do que os obtidos no presente trabalho na fase de estocagem, quando somente um lote foi condenado e mesmo assim ao final de 30 dias de armazenagem.

$\mathrm{Na}$ presente pesquisa, o queijo foi obtido diretamente do laticínio previamente selecionado e imediatamente após a produção, sendo a temperatura de armazenamento rigidamente controlada $\left(4^{\circ} \mathrm{C}\right)$, ao contrário do trabalho de Carvalho, Viotto e Kuaye (2007), que obtiveram amostras já no mercado, com idades variadas e onde a temperatura de estocagem pode sofrer maior variação, o que pode explicar a diferença entre os resultados e reforça a necessidade de controle higiênico do produto na indústria e no varejo.

Mesmo sob refrigeração, as bactérias mesófilas (Tabela 1) apresentaram um crescimento gradativo em média de $7,72 \log$ UFC.g ${ }^{-1}$ entre o $1^{\circ}$ e $30^{\circ}$ dia no queijo armazenado 
a $4{ }^{\circ} \mathrm{C}$. A contagem dos microrganismos mesófilos tem sido usada como indicador da qualidade higiênica dos alimentos, fornecendo ideia sobre seu tempo útil de conservação (SILVA; JUNQUEIRA; SILVEIRA, 2001; JAY, 1994). Rosa (2004) analisou o queijo fresco e encontrou população de bactérias mesófilas de 6,48 log UFC.g-1 . Manolopoulou et al. (2003), trabalhando com queijo feta (queijo fresco da Grécia), obteve uma evolução das bactérias mesófilas de 5,18 a 9,35 log UFC.g-1 durante um período de 16 dias. O queijo em estudo (Tabela 1) apresentou uma contagem elevada destes microrganismos com população média final de $11,47 \log \mathrm{UFC}_{\mathrm{g}}{ }^{-1}$ no $30^{\circ}$ dia de armazenamento.

As bactérias lácticas durante o período de armazenamento apresentaram população inicial de 3,48 e 9,53 log UFC.g ${ }^{-1}$ no $30^{\circ}$ dia com crescimento médio final de 6,56 log UFC. $\mathrm{g}^{-1}$, mostrando um aumento de 6,05 log UFC. $g^{-1}$ entre o $1^{\circ}$ e o $30^{\circ}$ dia (Tabela 1 ). A evolução das bactérias lácticas durante este período foi elevada e poderia produzir alterações químicas e sensoriais do produto reduzindo a sua vida útil. A presença das bactérias lácticas pode ter sua origem no leite destinado à produção do queijo ou pela adição de cultura láctica durante o processamento do produto. O seu crescimento ocasiona o aumento da acidez pelo fato de fermentarem a lactose e formarem ácido láctico. As bactérias lácticas são responsáveis pelas transformações bioquímicas de lipídios e proteínas em diferentes compostos desenvolvendo flavor, caracterizando o produto final quanto ao sabor, aroma e textura (ESKIN, 1990).

Nas amostras analisadas, a população de bactérias lácticas verificada (Tabela 1) foi próxima aos valores encontrados nos trabalhos de Rocha, Buriti e Saad $(2005,2006)$, os quais avaliaram o comportamento das bactérias lácticas em queijo Minas frescal de sete diferentes marcas durante a vida de prateleira por 21 dias, quando seis marcas apresentaram uma população média final de aproximadamente $8,0 \log$ UFC. $g^{-1}$ e não apresentaram crescimento com o passar dos dias. Manolopoulou et al. (2003), durante um período de 16 dias trabalhando com queijo feta, também detectou um aumento da população de bactérias lácticas do gênero Leuconostoc de 3,76 a 9,97 log UFC.g ${ }^{-1}$.

Ainda na Tabela 1, podem-se observar as evoluções das populações das bactérias psicrotróficas totais, psicrotróficas lipolíticas e psicrotróficas proteolíticas apresentando um aumento médio final da população de 8,50, 8,30 e 8,04 log UFC.g ${ }^{-1}$ entre o $1^{\circ}$ e o $30^{\circ}$ dia de armazenamento, respectivamente.

O aumento da população de microrganismos psicrotróficos é justificado pela característica desses microrganismos crescerem em temperaturas de 2 a $7{ }^{\circ} \mathrm{C}$. Rosa (2004) encontrou em queijo Minas frescal uma população de 7,09 log UFC.g ${ }^{-1}$ de bactérias psicrotróficas aeróbias totais, valor que é próximo a 6,49 log UFC.g ${ }^{-1}$ encontrado por Lisita (2005), que são próximos aos valores encontrados neste trabalho, conforme é observado na Tabela 1.

Morales, Fernández-García e Nuñez (2005) identificaram 122 compostos voláteis (aldeídos, cetonas, ésteres, alcoóis, hidrocarbonetos, compostos benzênicos e compostos sulfurosos) em queijos inoculados com uma população de 5,0 log UFC.g ${ }^{-1}$ de bactérias do gênero Pseudomonas e armazenados por 12 dias a $10^{\circ} \mathrm{C}$. Estes microrganismos produzem enzimas extracelulares (lipases e proteases) as quais, por reações bioquímicas, produzem compostos alterando o produto e limitando a vida de prateleira (MOURA, 1997, FRANK; CHRISTEN; BULLERMAN, 2005). Geralmente o alto número de bactérias psicrotróficas reflete uma quantidade suficiente de proteases e lipases para causarem a quebra das proteínas e gordura (BARBANO; MART; SANTOS, 2006). O desenvolvimento dos microrganismos psicrotróficos lipolíticos e proteolíticos (Tabela 1) poderá, eventualmente, ocasionar alterações físico-químicas com o passar dos dias ficando visíveis e perceptíveis as mudanças quanto às características organolépticas do queijo.

\subsection{Análises físico-químicas e químicas}

A redução de $\mathrm{pH}$ foi de 6,66 a 5,85 $(0,81)$ entre o $1^{\circ}$ e o $30^{\circ}$ dia. O mesmo comportamento teve a acidez do queijo (Figura 1) com um aumento de $0,026 \%$ de ácido láctico entre o $1^{\circ}$ e o $30^{\circ}$ dia com diferença significativa entre as médias ao nível de $5 \%$.

Buriti, Rocha e Saad (2005) estudaram o queijo Minas frescal por um período de 21 dias armazenado à temperatura de $8^{\circ} \mathrm{C}$; também observaram uma redução no $\mathrm{pH}$ de 6,16 a 5,38 (diferença de 0,78 ) entre o $1^{\circ}$ dia e o $21^{\circ}$ dia de armazenamento e um aumento na acidez titulável em ácido láctico de $0,36 \%$. Silva et al. (2003) encontraram valores de pH de 6,2 a 5,0 em queijo Minas frescal, valores próximos aos encontrados no queijo em estudo.

O aumento da acidez está diretamente relacionado com o aumento da população dos microrganismos mesófilos, psicrotróficos e principalmente as bactérias lácticas, as quais são os principais agentes na transformação da lactose em ácido láctico. Na Figura 2 é relacionado o aumento da acidez do queijo Minas frescal armazenado por 30 dias a $4{ }^{\circ} \mathrm{C}$ ao aumento das contagens de bactérias lácticas, mesófilas e psicrotróficas.

A acidez do queijo tende a aumentar com a multiplicação dos microrganismos no decorrer do período de armazenamento, beneficiando o produto por inibir a microbiota patogênica (WOLFSCHOON-POMBO; LIMA, 1989). Conforme mostrado na Figura 2, houve uma correlação linear entre o aumento da população dos microrganismos e elevação da acidez.

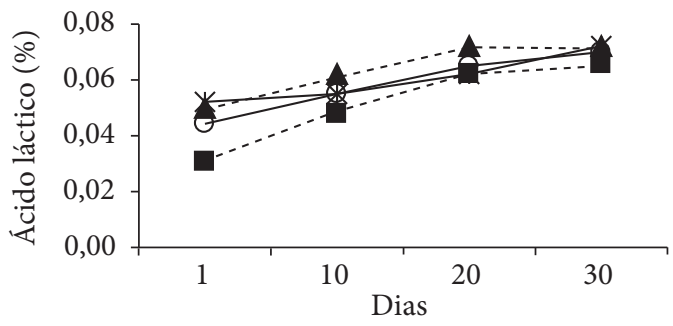

\begin{tabular}{|c|c|c|c|c|}
\cline { 2 - 5 } \multicolumn{1}{c|}{} & 1 & 10 & 20 & 30 \\
\hline - - Lote A & 0,031 & 0,048 & 0,062 & 0,066 \\
\hline * Lote B & 0,052 & 0,055 & 0,062 & 0,072 \\
\hline - L Lote C & 0,05 & 0,062 & 0,072 & 0,072 \\
\hline - $-\begin{array}{l}\text { Média } \\
\text { entre lote }\end{array}$ & 0,044 & 0,055 & 0,065 & 0,07 \\
\hline
\end{tabular}

Figura 1. Aumento da acidez no queijo Minas frescal durante o armazenamento por 30 dias a $4^{\circ} \mathrm{C}$. 
Tabela 1. Evolução da população dos microrganismos patogênicos e indicadores em queijo Minas frescal durante 30 dias de armazenamento a $4{ }^{\circ} \mathrm{C}$.

\begin{tabular}{|c|c|c|c|c|c|}
\hline \multirow{3}{*}{ Escherichia coli NMP.g ${ }^{-1}$} & Lotes & $1^{\circ} \mathrm{dia}$ & $10^{\circ} \mathrm{dia}$ & $20^{\circ}$ dia & $30^{\circ} \mathrm{dia}$ \\
\hline & A & $<3,0$ & $<3,0$ & $<3,0$ & $<3,0$ \\
\hline & $\mathrm{B}$ & $<3,0$ & $<3,0$ & $<3,0$ & $<3,0$ \\
\hline \multirow{4}{*}{ Staphylococcus coag. pos. UFC. ${ }^{-1}$} & $\mathrm{C}$ & $<3,0$ & 6,0 & $<3,0$ & $1,7 \times 10^{4}$ \\
\hline & A & $<10,0$ & $<10,0$ & $<10,0$ & $<10,0$ \\
\hline & $\mathrm{B}$ & $<10,0$ & $<10,0$ & $<10,0$ & $<10,0$ \\
\hline & $\mathrm{C}$ & $<10,0$ & $<10,0$ & $<10,0$ & $<10,0$ \\
\hline \multirow[t]{3}{*}{ Salmonella sp./25 g } & A & Ausência & Ausência & Ausência & Ausência \\
\hline & $\mathrm{B}$ & Ausência & Ausência & Ausência & Ausência \\
\hline & $\mathrm{C}$ & Ausência & Ausência & Ausência & Ausência \\
\hline \multirow[t]{3}{*}{ Bactérias piscrotróficas totais (log UFC.g ${ }^{-1}$ ) } & A & $2,52 \pm 0,33^{\mathrm{d}}$ & $8,09 \pm 0,20^{c}$ & $9,69 \pm 0,31^{\mathrm{b}}$ & $11,07 \pm 0,73^{\mathrm{a}}$ \\
\hline & $\mathrm{B}$ & $2,66 \pm 0,44^{\mathrm{d}}$ & $7,19 \pm 0,14^{c}$ & $10,08 \pm 0,76^{\mathrm{b}}$ & $11,46 \pm 0,09^{a}$ \\
\hline & $\mathrm{C}$ & $4,20 \pm 0,57^{\mathrm{d}}$ & $7,93 \pm 0,90^{c}$ & $10,47 \pm 0,37^{\mathrm{b}}$ & $12,37 \pm 0,34^{\mathrm{a}}$ \\
\hline \multirow[t]{3}{*}{ Bactérias piscrotróficas lipolíticas (log UFC.g ${ }^{-1}$ ) } & A & $2,30 \pm 0,42^{\mathrm{c}}$ & $7,29 \pm 0,38^{\mathrm{b}}$ & $8,20 \pm 0,17^{b}$ & $10,74 \pm 0,84^{\mathrm{a}}$ \\
\hline & $\mathrm{B}$ & $2,00 \pm 0,50^{c}$ & $6,57 \pm 0,47^{\mathrm{b}}$ & $9,23 \pm 0,65^{\mathrm{a}}$ & $8,42 \pm 0,82^{\mathrm{a}}$ \\
\hline & $\mathrm{C}$ & $1,82 \pm 0,72^{\mathrm{d}}$ & $8,53 \pm 0,39^{c}$ & $10,04 \pm 0,61^{\mathrm{b}}$ & $11,87 \pm 0,35^{\mathrm{a}}$ \\
\hline \multirow[t]{3}{*}{ Bactérias psicrotróficas proteolíticas (log UFC. $\mathrm{g}^{-1}$ ) } & A & $2,08 \pm 0,12^{\mathrm{d}}$ & $6,42 \pm 0,30^{c}$ & $8,22 \pm 0,48^{b}$ & $10,17 \pm 0,44^{\mathrm{a}}$ \\
\hline & $\mathrm{B}$ & $1,00 \pm 0,00^{c}$ & $5,61 \pm 0,13^{\mathrm{b}}$ & $7,56 \pm 0,54^{\mathrm{a}}$ & $7,67 \pm 0,26^{\mathrm{a}}$ \\
\hline & $\mathrm{C}$ & $2,04 \pm 0,64^{\mathrm{d}}$ & $6,13 \pm 0,70^{c}$ & $8,94 \pm 0,74^{\mathrm{b}}$ & $11,41 \pm 0,44^{\mathrm{a}}$ \\
\hline \multirow[t]{3}{*}{ Bactérias lácticas (log UFC.g $\left.{ }^{-1}\right)$} & A & $2,52 \pm 0,24^{\mathrm{a}}$ & $6,3 \pm 0,86^{\mathrm{a}}$ & $7,62 \pm 0,70^{\mathrm{b}}$ & $7,65 \pm 0,07^{c}$ \\
\hline & B & $3,04 \pm 0,42^{\mathrm{a}}$ & $6,14 \pm 0,57^{b}$ & $7,9 \pm 0,19^{c}$ & $11,14 \pm 0,24^{\mathrm{d}}$ \\
\hline & $\mathrm{C}$ & $4,88 \pm 0,49^{\mathrm{a}}$ & $5,34 \pm 0,25^{\mathrm{b}}$ & $6,40 \pm 0,25^{c}$ & $9,79 \pm 0,34^{c}$ \\
\hline \multirow[t]{3}{*}{ Bactérias mesófilas aeróbios totais (log UFC. $\mathrm{g}^{-1}$ ) } & A & $3,59 \pm 0,28^{\mathrm{a}}$ & $7,02 \pm 0,38^{\mathrm{b}}$ & $8,57 \pm 0,50^{c}$ & $11,40 \pm 0,85^{\mathrm{d}}$ \\
\hline & $\mathrm{B}$ & $2,75 \pm 0,19^{a}$ & $6,48 \pm 0,38^{\mathrm{b}}$ & $9,28 \pm 0,12^{\mathrm{c}}$ & $11,62 \pm 0,58^{\mathrm{d}}$ \\
\hline & $\mathrm{C}$ & $4,91 \pm 0,21^{\mathrm{a}}$ & $7,09 \pm 0,76^{b}$ & $9,34 \pm 1,47^{c}$ & $11,40 \pm 0,27^{\mathrm{d}}$ \\
\hline
\end{tabular}

${ }^{1}$ Resultados relativos à média \pm desvio padrão de duas peças de queijo para amostras analisadas em duplicatas nos dias 1, 10, 20 e 30 após o dia de fabricação.

${ }^{a, b, c}$ Médias seguidas de diferentes letras nas linhas diferem estatisticamente pelo teste de Tuckey ao nível de significância 5\%.

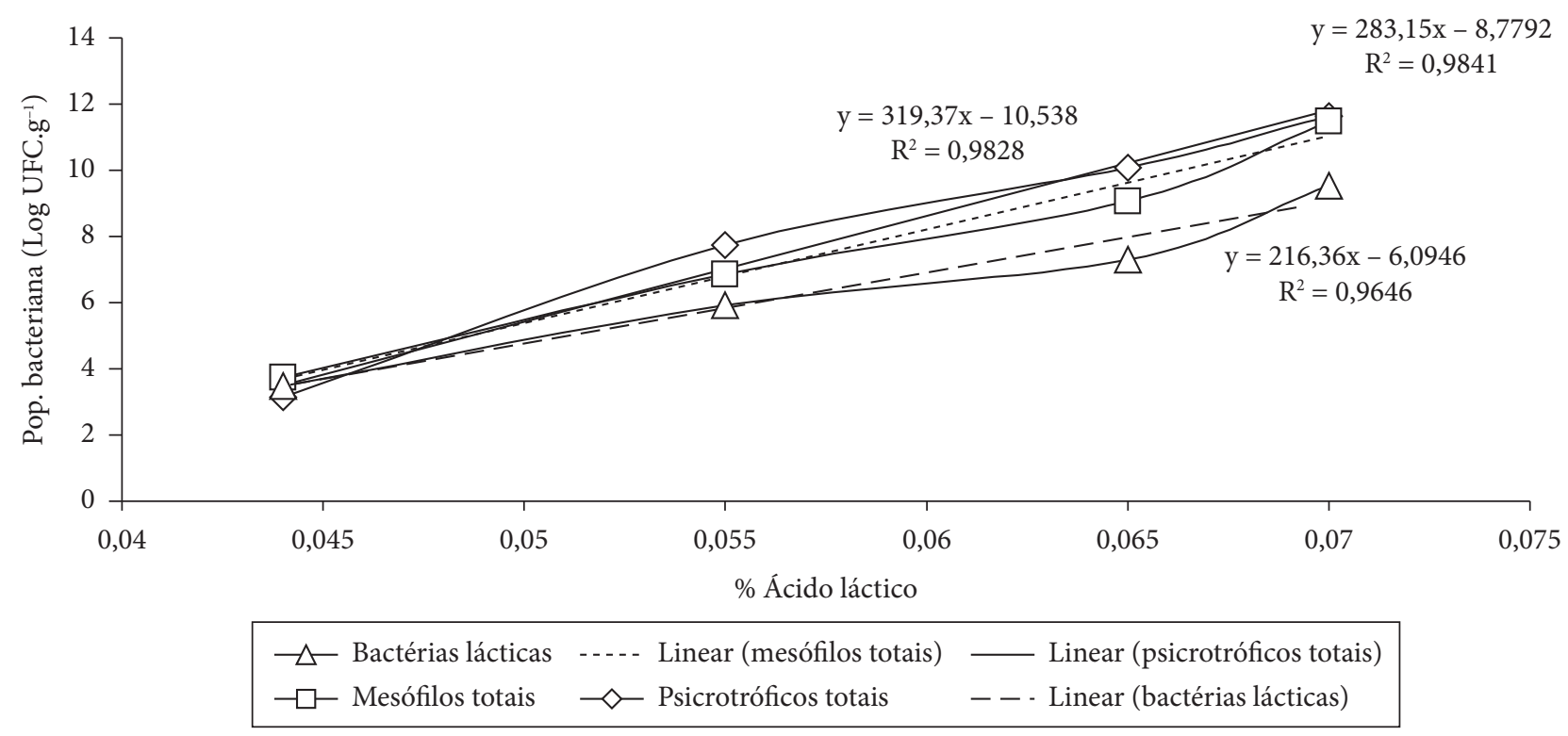

Figura 2. Correlação linear entre o aumento de ácido láctico e o crescimento da população de bactérias psicrotróficas totais, mesófilas totais e as bactérias lácticas no queijo Minas frescal armazenado por 30 dias a $4{ }^{\circ} \mathrm{C}$. 
A gordura do queijo não teve variação estatística significativa ao nível de 5\%, apresentando uma média final de 21,25\% no decorrer de 30 dias. Valores semelhantes a este foram encontrados por Rosa (2004) (20,5\%) e Furtado e Lourenço Neto (1994) (23 a $25 \%$ de gordura).

Os resultados obtidos para a lipólise apresentaram diferença significativa entre o $1^{\circ}$ e o $30^{\circ}$ dia de armazenamento, mostrando um aumento de $0,22 \mathrm{mg} \mathrm{KOH} . \mathrm{g}^{-1}$ de gordura dos ácidos graxos livres com o passar dos dias (Figura 3). Esta evolução pode ser relacionada à proliferação das bactérias psicrotróficas lipolíticas e das bactérias lácticas, as quais produzem enzimas lipolíticas

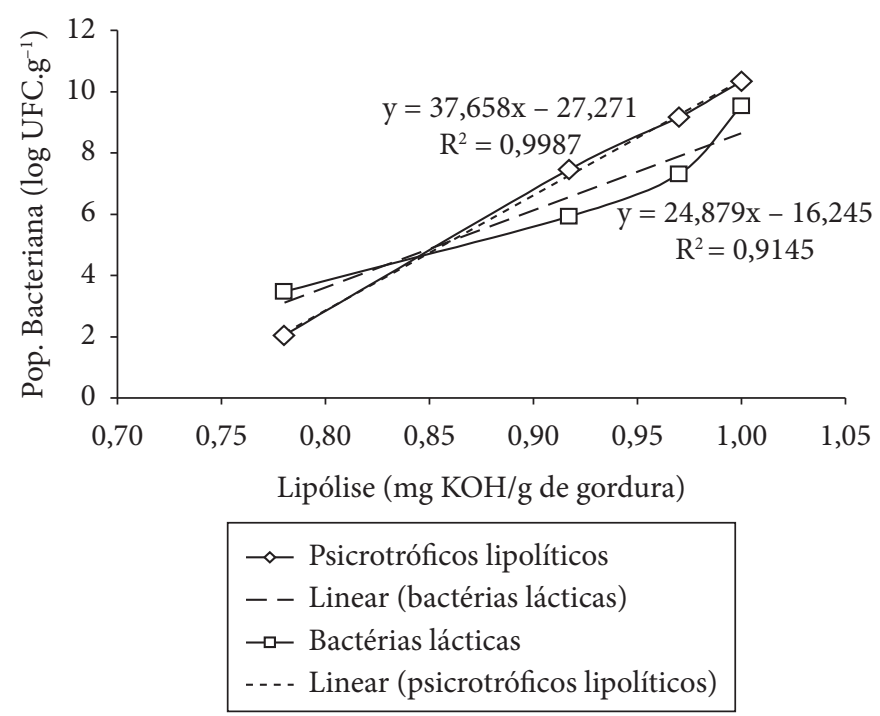

Figura 3. Comparativo entre o aumento da lipólise e o crescimento das populações de bactérias psicrotróficas lipolíticas e bactérias lácticas verificados a cada dez dias $\left(1^{\circ}, 10^{\circ}, 20^{\circ}\right.$ e $30^{\circ}$ dia $)$ no queijo Minas frescal armazenado a $4{ }^{\circ} \mathrm{C}$.

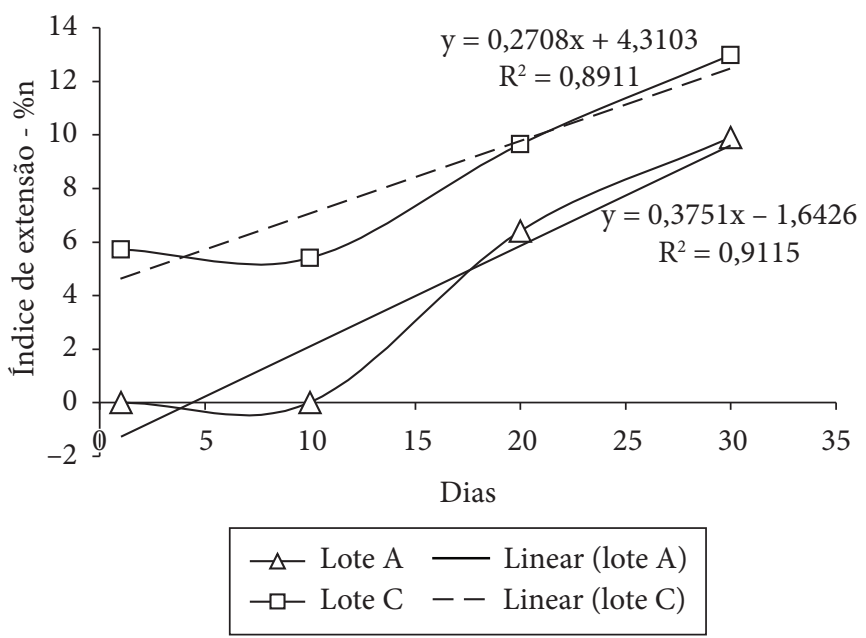

Figura 4. Evolução do índice de extensão da hidrólise verificada a cada dez dias $\left(1^{\circ}, 10^{\circ}, 20^{\circ}\right.$ e $30^{\circ}$ dia $)$ no queijo Minas frescal armazenado a $4{ }^{\circ} \mathrm{C}$. responsáveis em hidrolisar lipídios liberando ácidos graxos livres entre outros compostos voláteis (HOLLAND, et al. 2005).

A porcentagem média de proteína encontrada no queijo armazenado por 30 dias a $4{ }^{\circ} \mathrm{C}$ variou de 21,29 a $22,10 \%$ não apresentando diferença estatística do $1^{\circ}$ ao $30^{\circ}$ dia. Spadoti, Dornellas e Roig (2005) e Machado et al. (2004) encontraram 18,02 e 17,06\% de proteína em queijo Minas frescal, respectivamente. Esta diferença aproximada de 4,0\% de proteína entre os autores citados e o presente trabalho pode ser devido à não padronização do produto, à qualidade da matéria-prima ou pelo teor de umidade.

O índice de extensão da hidrólise apresentado no lote A não foi detectado no $1^{\circ}$ e $10^{\circ}$ dia de armazenamento, mas no $20^{\circ}$ dia o valor encontrado foi de $6,40 \%$, o qual aumentou para 9,91\% no $30^{\circ}$ dia. No lote $\mathrm{C}$ o índice de extensão da hidrólise diferiu entre si de forma crescente entre o $10^{\circ}$, o $20^{\circ}$ e o $30^{\circ}$ dia, sendo que a diferença foi de 4,26 e 3,32\%, respectivamente. Os resultados da hidrólise do Lote $\mathrm{B}$ não foram consistentes e não foram utilizados.

Saboya et al. (1998) encontraram valores próximos ao presente trabalho ao observarem a evolução do índice de proteólise de 7,59 a 13,03\% num período de 21 dias em queijo Minas frescal. Da mesma forma Isepon e Oliveira (1993) encontraram 4,99\% no primeiro dia de armazenamento e de $10,71 \%$ após o $13^{\circ} \mathrm{dia}$. $\mathrm{Na}$ Figura 4 é observada a evolução do índice de extensão durante o tempo de armazenamento dos lotes $\mathrm{A}$ e $\mathrm{C}$.

O índice de extensão da hidrólise está relacionado com as proteinases naturais do leite e do agente coagulante, as quais degradam as proteínas em peptídeos de alto peso molecular (ANDREATTA, 2006). Com o passar dos dias a hidrólise pode continuar e o produto pode ter suas características organolépticas alteradas.

\section{Conclusões}

Um dos lotes tornou-se impróprio para o consumo no $30^{\circ}$ dia mesmo sob refrigeração a $4^{\circ} \mathrm{C}$ por excesso de E. coli, o que demonstra a necessidade de uma excelente higiene na fabricação do produto para que o queijo possa atender aos padrões sanitários durante a armazenagem por 30 dias a $4{ }^{\circ} \mathrm{C}$. As populações de microrganismos mesófilos, psicrotróficos totais, lipolíticos e proteolíticos, assim como a população de bactérias lácticas, aumentaram constantemente durante o período de 30 dias de armazenagem a $4{ }^{\circ} \mathrm{C}$. A evolução da lipólise foi concomitante com o crescimento dos microrganismos psicrotróficos lipolíticos.

\section{Referências bibliográficas}

ANDREATTA, E. Avaliação da qualidade dos queijos Minas frescal e tipo Mussarela produzidos com leite contendo diferentes níveis de células somáticas. Pirassununga, 2006. 110 p. Tese (Doutorado em Qualidade e Produtividade Animal) - Faculdade de Zootecnia e Engenharia de Alimentos, Universidade de São Paulo.

AMERICAN PUBLIC HEALTH ASSOCIATION - APHA. Standard methods for the examination of dairy products. Washington, 1992. $345 \mathrm{p}$. 
ÁVILA, C. R. de; GALLO, C. R. Pesquisa de Salmonella spp. em leite cru, leite pasteurizado tipo C e queijo Minas frescal comercializados no município de Piracicaba - SP. Scientia Agrícola, v. 53, n. 1, jan./abr., 1996

BARBANO, D. M.; MART, Y.; SANTOS, M. V. Influence of raw milk quality on fluid milk shelf life. Journal of Dairy Science, v. 89, (E. Suppl.), p. E15-E19, 2006.

BRASIL. Ministério da Saúde. Agência Nacional de Vigilância Sanitária (ANVISA). Resolução - RDC n. 12, de 02 de janeiro de 2001. Regulamento técnico sobre padrões microbiológicos para alimentos. Diário Oficial da União, Brasília, 02 de janeiro de 2001.

BRASIL. Ministério da Agricultura, Pecuária e Abastecimento. Decreto $n^{\circ} 2244$, de 04 de junho de 1997. Regulamento de inspeção industrial e sanitária de produtos de origem animal (RIISPOA). Diário Oficial da União, Brasília, 04 de junho de 1997.

BURITI, F. C. A.; ROCHA, J. S.; SAAD, S. M. I. Incorporation of Lactobacillus acidophilus in Minas fresh cheese and implicatons for textural and sensorial properties during storage. International Dairy Journal, v. 15, n. 12, p. 1279-1288, Dez. 2005.

CABONI, M. F.; ZANNONI, M.; LERCKER, G. Fat lipolysis in Parmigiano-Reggiano cheese. Scienza e Tecnica Lattiero Casearia, v. 41, Suplemento, p. 289-297, 1990.

CARVALHO, J. D. G.; VIOTTO, W. H.; KUAYE, A. Y. The quality of Minas frescal cheese produced by different technological processes. Food Control, v. 18, n. 3, p. 262-267, Mar. 2007.

CHAVES, J. B. P. Noções de microbiologia e conservação de alimentos. 2 ed. Viçosa: Universidade de Viçosa, 1993. 114 p.

ESKIN, M. N. A. Biochemistry of foods. 2 ed. London: Academic Press, 1990. 557 p.

FOX, P. F. et al. Fundamentals of cheese science. Gaithersburg: AN Aspen Publication, 2000. 587 p.

FRANCO, B. D. G. M.; LANDGRAF, M. Microbiologia de alimentos. São Paulo: Atheneu, 1999. 182 p.

FRANK, J. F.; CHRISTEN, G. L.; BULLERMAN, L. B. Tests for groups of microorganisms. In: MARSHALL, R. T. Standard methods for the examination of dairy products. Washington: American Public Health Association, 2005. p. 271-286.

FLOWERS, R. S. et al. Pathogens in milk and milk products. In: MARSHALL, R. T. Standard methods for the examination of dairy products. Washington: American Public Health Association, 2005. p. 103-212.

FURTADO, M. M. Principais problemas dos queijos: causas e prevenção. Edição Revisada e Ampliada. São Paulo: Fonte Comunicação e Editora, 2005. 200 p.

FURTADO, M. M.; CHANDAN, R. C. Efeito do teor de gordura na maturação de um queijo por Penicillium caseicolum. Revista do Instituto de Laticínios Cândido Tostes, v. 38, n. 225, p. 13-22, jan./fev. 1983.

FURTADO, M. M.; LOURENÇO NETO, J. P. de M. Tecnologia de queijos. São Paulo: Dipemar, 1994. 112p. (Manual técnico para a produção industrial de queijos).

GRIPON, J. C. et al. Etude du role dês micro-organismes et des enzymes are cours de la maturation des fromages. Le lait, v. 55, p. 502-512, 1975.

HITCHINS, A. D.; HARTMAN, P. A.; TODD, E. C. D. Coliforms Escherichia coli and its toxins. In: VANDERZANT, C.; SPLITTSTOESSER, R. F. 3 ed. Compendium of methods for the microbiological examination of foods. Washington: American Public Health Association, 1992. p. 325-369.
HOFFMAN, F. L.; SILVA, J. V. da; VINTURIM, T. M. Qualidade microbiológica e queijos tipo "Minas frescal", vendidos em feiras livres na região de São José do Rio Preto, SP. Higiene Alimentar, v. 16, n. 96, p. 69-76, mai. 2002.

HOLLAND, R. et al. Esterases of lactic acid bactéria and cheese flavour: milk fat hidrolysis, alcoholysis and esterification. International Dairy Journal, v. 15, n. 6-9, p. 711-718, jun./sep. 2005.

ISEPON, J. S.; OLIVEIRA, A. J. Influência das culturas lácticas no índice de proteólise do queijo Minas frescal. Ciência Agrícola, v. 50, n. 3, p. 451-454, out./dez. 1993.

JAY, J. M. Microbiologia moderna de los alimentos. Zaragoza: Editora Acribia, 1994. 492 p.

LISITA, M. O. Evolução da população bacteriana na linha de produção do queijo Minas Frescal em uma indústria de laticínios. Piracicaba, SP. 2005.61 p. Dissertação (Mestrado) - Escola Superior de Agricultura "Luiz de Queiroz", Universidade de São Paulo.

MACHADO, E. C. et al. Características físico-químicas e sensoriais do queijo Minas artesanal produzido na região do Serro, Minas Gerais. Ciência e Tecnologia de Alimentos, v. 24, n. 4, p. 516-521, out./dez. 2004.

MANOLOPOULOU, E. et al. Evolution of microbial populations during traditional Feta cheese manufacture and ripening. International Journal of Food Microbiology, v. 82, n. 2, April 2005.

MARQUES, M. C.; OLIVEIRA, C. A. F. Avaliação das características físico-químicas do queijo Minas frescal produzido com leite contendo diferentes níveis de células somáticas. Pirassununga: FZEA/USP, 2004. 15 p. (Iniciação Científica).

MCSWEENEY, P. L. H.; SOUSA M. J. Biochemical pathways for the prodction of flavour compounds in cheese during ripening: a review. Le Lait, v. 80, p. 293 - 324, 2000.

MORALES, P.; FERNÁNDEZ-GARCÍA, E.; NUÑEZ, M. Volatile compounds produced in cheese by Pseudomonas strains of dairy origin belonging to six different species. Journal of Agricultural and Food Chemistry, v. 53, p. 6835-6843, 2005.

MOURA, C. J. Efeito do resfriamento do leite sobre o rendimento e lipólise do queijo tipo parmesão. Lavras, MG, 1997. 77 p. Dissertação (Mestrado em Ciência dos Alimentos) - Universidade Federal de Lavras, 1997.

PICOLI, S. U. et al. Quantificação de coliformes, Staphylococcus aureus e mesófilos presentes em diferentes etapas da produção de queijo frescal de leite de cabra em laticínios. Ciência e Tecnologia dos Alimentos, v. 1, n. 26, p. 64-69, jan./mar. 2006.

PERRY, K. S. P. Queijos: aspectos químicos, bioquímicos e microbiológicos. Química Nova, v. 27, n. 2, p. 293-300, 2004.

ROBINSON, R. K. Microbiologia de la leche. Madrid: Acribia, 1987. $230 \mathrm{p}$.

ROCHA, J. S.; BURITI, F. C. A.; SAAD, S. M. I. Condições de processamento e comercialização de queijo de Minas frescal. Arquivo Brasileiro de Medicina Veterinária e Zootecnia, v. 58, n. 2, p. 263-272, 2006.

ROSA, V. P. Efeitos da atmosfera modificada e da irradiação sobre as características microbiológicas, físico-químicas e sensoriais do queijo Minas frescal. Dissertação (Mestrado em Ciência e Tecnologia de Alimentos) - Escola Superior de Agricultura Luiz de Queiroz, Universidade de São Paulo.

SABOYA, L. V. et al. Efeitos físico-químicos da adição de leite reconstituído na fabricação de queijo Minas frescal. Ciência e Tecnologia de Alimentos, v. 18, n. 4, p.368-378, out./dez. 1998.

SANTOS, F. A.; NOGUEIRA, N. A. P.; CUNHA, G. M. Aspectos microbiológicos do queijo tipo coalho comercializado em Fortaleza CE. Boletim Centro de Pesquisa e Processamento de Alimentos, v. 13, n. 1, p. 31-36, jan./jun. 1995. 
SAS INSTITUTE. SAS user's guide: statistic. 6 ed. Cary: SAS Institute, 1998. $584 \mathrm{p}$.

SANTOS, F. A.; NOGUEIRA, N. A. P.; CUNHA, G. M. Aspectos microbiológicos do queijo tipo coalho comercializado em Fortaleza CE. Boletim Centro de Pesquisa e Processamento de Alimentos, v. 13, n. 1, p. 31-36. jan./jun. 1995.

SILVA, I. M. M. et al. Occurrence of Listeria ssp. in critical control points and the environment of Minas Frescal cheese processing. International Journal of Food Microbiology, v. 81, p. 241-248, 2003.

SILVA, N. da; JUNQUEIRA, V. C. A.; SILVEIRA, N. F. A. Manual de métodos de análise microbiológica de alimentos. São Paulo: Livraria Varela, 2001. 105 p.

SIQUEIRA, R. S. Manual de Microbiologia de Alimentos. Brasília: EMBRAPA - SPI; Rio de Janeiro: EMBRAPA - CTAA, 1995. 159 p.
SPADOTI, L. M.; DORNELLAS, J. R. F.; ROIG, S. M. Avaliação sensorial de queijo prato obtido por modificações do processo tradicional de fabricação. Ciência e Tecnologia dos Alimentos, v. 25, n. 4, p. 705-712, out./dez. 2005.

VARNAN, A. H.; SUTHERLAND, J. P. Leche y productos lácteos: tecnologia, química y microbiologia. Zaragoza: Acribia, SA, 1994. $476 \mathrm{p}$.

WOLFSCHOON-POMBO, A. L. Índice de proteólise em alguns queijos brasileiros. Boletim do Leite e seus Derivados, v. 56, n. 61, p. 1-8, nov. 1983

WOLFSCHOON-POMBO, A. L.; LIMA, A. Extensão e profundidade da proteólise em queijo Minas Frescal. Revista do Instituto de Laticínios Cândido Tostes, v. 44, n. 261-266, p. 50-52, 1989. 